International Journal of Mental Health and Addiction (2021) 19:2411-2422 https://doi.org/10.1007/s11469-020-00336-7

\title{
Psychometric Validation of the Persian Version of the Problem Gambling Severity Index
}

\author{
Mark D. Griffiths ${ }^{1} \cdot$ Nabi Nazari ${ }^{2}$ (D) \\ Published online: 9 June 2020 \\ (C) Springer Science+Business Media, LLC, part of Springer Nature 2020
}

\begin{abstract}
The Problem Gambling Severity Index (PGSI) has been the most frequently used instrument for prevalence studies for problem gambling in recent years. To date, there have been very few gambling studies among Persian populations. The objective of the present study was to investigate the reliability and validity of the Persian version of the PGSI. The original version of the PGSI was translated and back-translated into Persian, followed by a pilot study. A sample of Iranian online gamblers $(n=858)$ was recruited utilizing social media platforms. Results showed that the Persian PGSI had excellent internal consistency (Cronbach's alpha coefficient $=0.90$; composite reliability $=0.91$ ) and moderate test-retest reliability after 4-6 weeks using intraclass coefficient (0.41 with $95 \%$ CI $[.34, .49])$. The maximum likelihood confirmatory factor analysis for one-factor PGSI model fitted well $\left(\chi^{2} / d f=2.81, \mathrm{CFI}=.974, \mathrm{SRMR}=.028, \mathrm{PCLOSE}>.05, \mathrm{RMSEA}=.057,90 \%\right.$ CI $[.037$, $.077])$. As for criterion-related validity, the Persian PGSI score correlated with the score on the Hospital Anxiety Depression Scale, which assesses depression $(r=.54, p<.01)$ and anxiety $(r=.40, p<.01)$. The Persian PGSI is a reliable and valid instrument for assessing the prevalence of problem gambling among Persian populations.
\end{abstract}

Keywords: Gambling, internet gambling, validation, Problem Gambling Severity Index, gambling prevalence, Iranian gambling

\section{Introduction}

Gambling is a recreational activity, morally acceptable, and normative behavior in most countries. With growing awareness of gambling harms, problem gambling is increasingly recognized as a significant public health issue (Calado, Alexandre, Rosenfeld, Pereira, \& Griffiths, 2019), particularly among youth (Latvala, Lintonen, \& Konu, 2019). Problem gambling is defined as gambling that is disruptive with adverse impacts to gamblers, their families, and the 
community or interferes with their daily life (Gambling Commission, 2019). Even at low-risk levels, problem gambling (PG) can be associated with negative physical or psychosocial consequences and loss of quality of life (Wardle, Reith, Langham, \& Rogers, 2019). Also, a recent investigation of the Diagnostic and Statistical Manual of Mental Disorders (DSM-5; American Psychiatric Association [APA], 2013) gambling disorder criteria indicated that over $40 \%$ of those engaged in treatment for gambling reported engaging in illegal activities (Heinz, RomanczukSeiferth, \& Potenza, 2019).

According to a recent systematic review, the prevalence rates of PG across different jurisdictions range between $0.1 \%$ to $5.8 \%$ (Calado \& Griffiths, 2016). Some claim the problem has become more widespread in the past year, with considerable variability (Jonsson, 2019). However, a direct comparison of prevalence rates is also difficult due to methodological issues such as the many different problem gambling screens used in the prevalence studies (Calado \& Griffiths, 2016; Jonsson, 2019).

The Problem Gambling Severity Index (PGSI; Ferris \& Wynne, 2001) is an evidencebased instrument that was specifically developed for epidemiological prevalence studies of problem gambling among general populations (Otto et al., 2020; Stevens \& Young, 2008). In the DSM-5, gambling disorder (formerly known as pathological gambling) is a condition characterized by persistent problematic gambling behavior that leads to clinically significant impairment or distress (American Psychiatric Association, 2013). In the 1980s and 1990s, the most used problem gambling screens were the South Oaks Gambling Scale (SOGS; Lesieur \& Blume, 1987), and the various DSM screens (American Psychiatric Association, 2000).

At the level of the individual, problem gambling screens such as the PGSI and the SOGS include several items assessing both financial and legal consequences arising from gambling. As aforementioned, the SOGS has been one of the most widely used scales for assessing problem gambling to date, and the psychometric properties of the scale have been excellent in some studies 
(González-Roz, Fernández-Hermida, Weidberg, Martínez-Loredo, \& Secades-Villa, 2017). However, prevalence rates of problem gambling using the SOGS tends to be higher than diagnostic rates using the DSM criteria among similar populations and is not suitable for adolescents and some cross-cultural participants (Zhang, Shi, \& Tao, 2017). Regarding gambling consequences, the harms of gambling can occur without respondents meeting the clinical criteria (Browne, Goodwin, \& Rockloff, 2018). Therefore, the PGSI can be a potentially more meaningful assessment of problem gambling for use in the general population surveys with more indicators of the social and environmental context of gambling and problem gambling (Stinchfield, 2013).

To date, empirical research concerning gambling has received poor attention in Iran. One of the reasons for this neglect is that traditional gambling was not considered as a problematic issue because there are no land-based gambling venues in the country (e.g., casinos, bookmakers). The roles of the social acceptance (Derevensky, Shek \& Merrick. 2012), legalized gambling, and advertising (Newall et al., 2019) have been associated as underlying factors in gambling growth, but has been limited by the Iranian government and religious practices. At present, all forms of gambling are banned by law, including all related proceeds and activities (e.g., gambling marketing and advertising). Due to strong religious beliefs, gambling is viewed as one of the most unacceptable activities, and in religious scriptures, gamblers are described as irresponsible, outcasts, and outlaws. However, in contrast with traditional gambling, in recent years, the rapid growth of Persian gambling websites has arisen due to internet availability. Despite online gambling being prohibited by the Iranian government, there is a loophole. Online companies hosted outside of Iran, where the government has no jurisdiction, allow people from within Iran to visit their sites and gamble online. These sites allow Iranians the opportunity to bet on their favorite sports team, poker, bingo, roulette, blackjack, video slots, and other sensational poker games. The sport bets typically involve in-play betting (see Killick and Griffiths [2019] for a review). 
Furthermore, youth gambling prevalence rates in most jurisdictions have increased as availability, accessibility, and social acceptance have risen (Calado, Alexandre \& Griffiths, 2017; Volberg, Gupta, Griffiths, Ólason, \& Delfabbro, 2010). Importantly, internet gambling may be more likely to contribute to problem gambling than traditional offline gambling among vulnerable groups (Hubert \& Griffiths, 2019). In preliminary observations concerning online gambling in Iran, there are a large number of online forums in which members talk with each other about upcoming sporting events, and in-play betting particularly.

Recently, the Persian version of the Gambling Disorder Screening Questionnaire (GDSQP) was validated with acceptable psychometric properties (Maarefvand et al., 2019). However, the GDSQ-P was developed for clinical populations based on DSM-5 criteria to screen for gambling disorder, whereas the PGSI was developed for non-clinical populations, so there is good rationale for validating a non-clinical instrument in an Iranian context. The present study was carried out because it is necessary to validate a scale for problem gambling among Persian populations. Therefore, the present study attempted to validate a Persian version of PGSI and evaluate its psychometric properties.

\section{Method}

\section{Participants}

A sample of Persian online gamblers was recruited from online gambling communities in various social media platforms. A sample of 858 respondents (625 males; 233 females) aged between 18 and 50 years participated (mean age=27.2 years; $\mathrm{SD}=6.3$ years). The demographic characteristics of the sample are shown in Table 1. The inclusion criteria were being over the age of 18 years, being a Persian native, and having gambled at least once in the past year. In total, 
858 usable surveys were returned and used in data analysis. Participants were ensured anonymity and confidentiality and were explicitly asked not to provide their names or other personal identification information. They were notified that they could decline their participation at any time.

\section{Table 1}

\section{Measures}

Problem Gambling Severity Index (PGSI): The PGSI Ferris \& Wynne, 2001) is a nineitem problem gambling screen. Items (e.g., "Have you bet more than you could really afford to lose?") are responded to on a four-point Likert scale from 0 (never) to 3 (always) and assess the extent to which gamblers have experienced any psychosocial harms over the past 12 months. Higher scores indicate greater gambling risk. On the basis of PGSI scores, gamblers are classed into one of four groups: non-problem gamblers (scoring 0); low-risk gamblers (scoring 1-2); moderate-risk gamblers (scoring 3-7); and problem gamblers (scoring 8+). The Cronbach's alpha of the original PGSI was very good (0.84), with a four-week test-retest correlation of $r=.78$ (Ferris \& Wynne, 2001). PGSI scores are highly correlated with the scores on the SOGS and DSM-IV (Cowie et al., 2017; Orford, Wardle \& Griffiths, 2010)

The Hospital Anxiety and Depression Scale (HADS): The HADS (Zigmond \& Snaith, 1983; Persian version: Montazeri, Vahdaninia, Ebrahimi, \& Jarvandi, 2003) is a highly reliable scale for assessing anxiety and depression. The HADS comprises 14 items consisting of two seven-item subscales for anxiety (HADS-A; e.g., "I have lost interest in my appearance”) and depression (HADS-D; e.g., " I feel tense or wound up"), with a four-point Likert scale from 0 (never) to 3 (always). The total score of 21 for each domain and higher scores indicate greater anxiety or depression on the respective subscale. This scale demonstrated good reliability in the present study $(\alpha=0.84)$.

\section{Procedure}


Ethics: Ethics approval was granted by the research team's Institutional Review Board (IRB) and the study was carried out according the Declaration of Helsinki guidelines. The IRB reviewed the research protocol to ensure participant confidentiality, sampling and obtaining inform consent. The study schedule of survey development stages and validation process is illustrated in Table 2.

\section{Table 2}

Development of the survey: Transcultural adaptation and content validity of the PGSI was performed based on the guidelines proposed by Beaton, Bombardier \& Guillemin (2000) in relation to the translation/back-translation process. Initially, Two Persian translators independently translated the PGSI from English to Persian. One of the translators was aware of the concepts being examined in the questionnaire being translated (addiction and gambling). The other translator was neither be aware nor informed of the concepts being quantified and had no medical or clinical background. To obtain a consensus version, an expert committee evaluated both versions to synthesize a consensual version. Then, a native English translator carried out a backward Persian-to-English translation of the consensual version, and this was subsequently compared with the original version. There were no major changes needed.

Pilot study: In the final stage, a pilot study was performed with 30 participants randomly selected from the target population to verify the feasibility of the web-based survey. To identify actual and potential linguistic, grammar, the ambiguity of the survey items, the participants were requested to offer their feedback on every item. According to participant feedback, the survey items were easy to read and understand. The median response time was less than five minutes.

Sampling: Sample recruitment in the present study followed the social media recruiting strategy outlined by McRobert et al. (2018). More specifically, (i) ten of the most popular Persian online communities for online gambling were identified according to the number of users. Of these, three groups were randomly selected; (ii) each of the three groups had public lists of the 
users in each community, and potential participants were randomly selected to take part in the study, and finally (iii) a generic online invitation letter was sent to each randomly selected user. All random sampling at each stage utilized a random number generator. Also, a public invitation letter was posted on the public wall of each community, seen by all users, periodically, on Saturday and Tuesday every week for 16 weeks. Over $50 \%$ of participants received and completed the survey in the first six weeks, 70\% by Week 11, and the remainder by Week 16 .

Sample size: The authors used Comrey and Lee's (2013) guidelines concerning a graded scale of sample sizes for scale development $[100=$ poor, $200=$ fair, $300=$ good, $500=$ very good, and over $1,000=$ excellent]. The study sample size $(\mathrm{N}=858)$ was more than suitable for the statistics used in the present.

\section{Data analysis}

There were no missing values in the assessed variables, and no imputation method was implemented. Distributions of frequency, cross-tabulations, Chi-square and the, and independent $t$-test and one-way ANOVA (where suitable) were conducted to test the difference between groups. Exploratory factor analysis (EFA) was conducted to define the underlying structure among the variables in the analysis (Tabachnick \& Fidell, 2014). EFA is not normally carried out on an established scale but because there are no previous epidemiological studies that have ever carried out in Iran examining gambling and because of the very different population culture from almost all previous validation studies, the authors believed that this might have an impact in terms of how the questions were answered. Therefore, an EFA was carried in this particular instance. EFA was conducted on a randomized split of the data in the sample $(n=429)$. The nine items of the PGSI were subjected to principal components analysis (PCA). Prior To performing PCA, Bartlett's test was conducted to test the hypothesis of sufficient correlation among the variables. Also, the Kaiser-Meyer-Olkin (KMO) was generated to measure of sampling adequacy with 0.6 suggested s minimum value (Tabachnick \& Fidell, 2014) 
A maximum likelihood $(M L)$ confirmatory factor analysis (CFA) was then conducted on the remaining $(n=429)$ participants using AMOS 24. The following values demonstrate an excellent fitting model (Hu \& Bentler, 1999): $1<\chi^{2} / d f<3$, comparative fit index (CFI) $>0.95$, root mean square error of approximation $($ RMSEA) $<0.06$, and standardized root mean square residual $($ SRMR $)<0.06$. All analyses were performed using SPSS version 25 (SPSS Inc., Chicago, IL) and AMOS version 24 with a two-sided 5\% level of significance.

A Cronbach's alpha reliability coefficient was generated to assess internal consistency. An intraclass correlation coefficient (ICC) was used to evaluate test-retest reliability. The composite reliability $(\mathrm{CR})$ was utilized for satisfactory reliability. Furthermore, the risk of multicollinearity among the PGSI items was controlled by the variance inflation factor (VIF) (Hair, Babin, Anderson\& black, 2018). In the present study, Cronbach alpha $>0.8, \mathrm{CR}>0.8$, the test-retest reliability $>0.7$, and $1<\mathrm{VIF}<3$ were considered as acceptable psychometric properties. Convergent validity was tested utilizing average extracted variance (AVE). An AVE of .5 or higher is a good rule of thumb, suggesting adequate convergence (Henseler, Hubona, \& Ray, 2016). Criterion-related validity was evaluated by Pearson correlation with respect to depression (HADS-D), and anxiety (HADS-A) scores. In respect to the HADS and the PGSI cutoff scores, we classified the respondents in the two categorical groups. Therefore, the binary logistic regression analysis was then generated to determine whether online gambling could be predicted from depression or anxiety.

\section{Results}

Males were significantly more likely than females to have gambled during the past year $\left(\chi^{2}=179.09, p<.001\right)$. However, there was no significant difference in the PGSI scores between males and females $(t(856)=1.56, p=.12)$. A one-way between-participants ANOVA was conducted to compare the effect of age on problem gambling level. There were no significant 
differences between mean age across all four groups of problem gambling levels $(\mathrm{F}(2,855)=.10$, $p=.91$ ). Also, students were significantly more likely to have gambled during the past year $\left(\chi^{2}=147.71, p<.001\right)$. According to the PGSI cut off scores, 191 participants $(22.3 \%)$ were identified as problem gamblers. Results also showed that $77 \%$ of the problem gamblers were males $(n=148), 42 \%$ of the problem gamblers were between 24 to 30 years old $(n=81)$, and $70 \%$ of the problem gamblers were students $(n=126)$ (see Table 1).

The Persian PGSI had acceptable dimensional quality. Principal component analysis (PCA) demonstrated the unidimensionality of the PGSI. The KMO verified the sampling adequacy for the analysis $(\mathrm{KMO}=0.915)$, which was well above the acceptable limit of 0.5 . Also, Bartlett's test of Sphericity was significant $(d f=36, p<.001)$. The one-factor had an eigenvalue of 4.98, explaining $54 \%$ of the variance. The scree plot indicated one-factor for the targeted sample (see Figure 1).

\section{Figure 1}

The ML confirmatory factor analysis (CFA) was performed to examine the structural validity of the nine-item PGSI construct. The CFA for the one-factor PGSI model fitted that data well $\left(\chi^{2} / d f=2.81, \mathrm{CFI}=.974, \mathrm{SRMR}=.028, \mathrm{PCLOSE}>.05, \mathrm{RMSEA}=.057,90 \%\right.$ CI $\left.[.037, .077]\right)$ (see Figure 2).

\section{Figure 2}

The Cronbach alpha of the scale indicated excellent internal reliability $(\alpha=0.902)$ with 95\% CI $[.89, .91]$ in total sample. Also, the Cronbach alpha if item deleted values and corrected item correlation values are shown in Table 3. The test-retest was evaluated by ICC. After four to six weeks of the validation study, the survey sent for half of the participants $(n=430)$ who were randomly selected by random number generator. Of these, $(\mathrm{N}=108)$ surveys returned. In terms of consistency, the ICC was .41 with $95 \%$ CI $[.34, .49]$ for the single measure and .92 with $95 \%$ CI $[.89, .94]$ for the average measure. The composite reliability was excellent $(\mathrm{CR}=.91)$. The 
convergent validity was acceptable (AVE=.51; $\mathrm{AVE}<\mathrm{CR})$. The Pearson correlation coefficients between problem gambling (PGSI score) and depression (HADS-D score; $r=.54, p<.01$ ), and anxiety (HADS-A score; $r=.40, p<.01$ ) were both positively and significantly correlated. The results of the binary regressions suggested that depression and anxiety were the predictors of the gambling among online gamblers $(p<.001)$.

\section{Table 3}

\section{Discussion}

The present study was designed to evaluate the validity and factor structure of the Persian Problem Gambling Severity Index (PGSI). The tool was also used to assess the prevalence of problem gambling among Persian online gamblers. The results of the study demonstrated that the PGSI is a valid and reliable instrument to assess problem gambling among the Persian population. The evaluation of content validity suggested that the Persian PGSI was acceptable. It also had excellent internal consistency, because all the Cronbach's alpha values were well above the accepted range. The results demonstrated the PGSI had a one-factor structure and the findings were consistent with those of previous psychometric validation studies in Italy (Colasante et al., 2013), China (Loo, Oei, \& Raylu, 2011), Spain (Lopez-Gonzalez, Estévez, \& Griffiths, 2018), and Japan (So, Matsushita, Kishimoto, \& Furukawa, 2019). Based on the findings, the Persian PGSI can be used in future prevalence studies of problem gambling in Iran and other Persianspeaking communities.

The PGSI includes indicators of both the social and environmental context of gambling and problem gambling behavior. The PGSI is suitable for community-based surveys and provides accurate estimates of problem gambling prevalence. The use of the Persian PGSI in future Iranian studies will make it easier to compare with the results of the recent prevalence studies in other countries (Calado \& Griffiths, 2016). 
A significant gender difference was found with males being more likely than females to have gambled in the past year. However, there was no significant difference in problem gambling severity, unlike most studies that have tended to find higher prevalence rates of problem gambling among males compared to females (Calado \& Griffiths, 2016). There were no significant differences between ages across all four groups of problem gambling levels. Although online problem gamblers are more likely to be young (Olason et al., 2010), age is not necessarily a reliable predictor of online problem gambling. Over $65 \%$ of the gamblers were identified as the moderate risk and problem gamblers in the present study, which is a high prevalence compared to nationally representative studies (Calado \& Griffiths, 2016). The high prevalence may have been due to the online medium (e.g., McCormack et al., 2013) and/or because the sample (while relatively large) was unrepresentative of online gamblers in (and outside of) Iran.

To evaluate criterion validity, problem gambling score on the PGSI was correlated against measures for depression (HADS-D), and anxiety (HADS-A). Results found significant positive correlations between PGSI and HADS-D and HADS-A. This finding is in line with recent studies, showing depression and anxiety are potential characteristics of online gamblers (Barrault, Bonnaire, \& Herrmann, 2017; Welte, Barnes, Tidwell, \& Wieczorek, 2017). Also, the PGSI has good criterion validity and has the potential to be used as an instrument to identify problem gambling symptoms among individuals.

The findings of the present study are important because gambling is a new phenomenon in Iranian contexts, particularly among emerging adults. Over $70 \%$ of the gamblers in the present study were students. Online gambling, with in-play sports betting, can be potentially more harmful than other types of gambling (Killick \& Griffiths, 2019). Depression and anxiety were the predictors of gambling among online gamblers, irrespective of the problem gambling intensities. 
The findings of the study must be interpreted in light of several limitations. As previously outlined, gambling is viewed as an undesirable behavior among the Iranian population. This meant that interviewing gamblers face-to-face was almost impossible because Iranians will not admit these types of activity to third parties (such as researchers who may be perceived as working for the law organizations). Therefore, the data collected had to be collected online which may be affected by common methods biases. The real number of individuals who received the invitation letter to participate is unknown, therefore, the response rate is also unknown. The participants were recruited among online gamblers that limits the generalizability of the findings because it was not necessarily a representative sample of online gamblers. Finally, gambling being illegal in Iran may have affected how some people responded to the questions and we have now added it as a limitation. The strengths of the study were the high reliability and validity values with excellent goodness of fit for the unidimensional factor structure of the Persian PGSI.

\section{Conclusion}

Results showed the Persian PGSI demonstrated good validity and a high level of reliability in assessing problem gambling among Persian online gamblers. Therefore, the Persian PGSI can be used among Persian-speaking communities to ensure uniformity and objectivity when assessing problem gambling and can be used to compare findings with that of other countries. Online gambling is a multifaceted issue, associated with psychosocial and financial harms. For Iran, because of religious beliefs and law, the assumption appears to be that if it is illegal, it is a behavior that is not engaged in but the present study clearly shows this not to be the case. The Iranian government needs to be aware that gambling is a very popular activity among some of its citizens because it can be easily accessed online. The Persian PGSI is a valid instrument to assess gambling-related harm in Iran and can be used in prevention and prevalence research in Iran, where problem gambling is a little-studied behavior. 


\section{References}

American Psychiatric Association. (2000). Diagnostic and statistical manual of mental disorders (fourth ed., text rev.). Washington, DC: Author.

American Psychiatric Association (2013). Diagnostic and statistical manual of mental disorders (fifth edition). Arlington, VA: American Psychiatric Publishing.

Barrault, S., Bonnaire, C., \& Herrmann, F. (2017). Anxiety, depression and emotion regulation among regular online poker players. Journal of Gambling Studies, 33(4), 1039-1050. https://doi.org/10.1007/s10899-017-9669-3

Beaton, D. E., Bombardier, C., Guillemin, F., \& Ferraz, M. B. (2000). Guidelines for the process of cross-cultural adaptation of self-report measures. Spine, 25(24), 31863191. https://doi.org/10.1097/00007632-200012150-00014

Browne, M., Goodwin, B. C., \& Rockloff, M. J. (2018). Validation of the short gambling harm screen (SGHS): A tool for assessment of harms from gambling. Journal of Gambling Studies, 34(2), 499-512. https://doi.org/10.1007/s10899-017-9698-y

Calado, F., Alexandre, J., Rosenfeld, L., Pereira, R., \& Griffiths, M. D. (2019). The efficacy of a gambling prevention program among high-school students. Journal of Gambling Studies. Epub ahead of print. https://doi.org/10.1007/s10899-019-09908-2

Calado, F., \& Griffiths, M. D. (2016). Problem gambling worldwide: An update and systematic review of empirical research (2000-2015). Journal of Behavioral Addictions, 5(4), 592-613. https://doi.org/10.1556/2006.5.2016.073

Colasante, E., Gori, M., Bastiani, L., Siciliano, V., Giordani, P., Grassi, M., \& Molinaro, S. (2013). An assessment of the psychometric properties of italian version of CPGI. Journal of Gambling Studies, 29(4), 765-774. https://doi.org/10.1007/s10899-0129331-z

Comrey, A. L., \& Lee, H. B. (2013). A first course in factor analysis. (2nd ed.). Hoboken, 
NJ: Taylor and Francis.

Corney, R., \& Davis, J. (2010). The attractions and risks of Internet gambling for women: A qualitative study. Journal of Gambling Issues, 8(24), 121-139. https://doi.org/10.4309/jgi.2010.24.8

Cowie, M. E., Stewart, S. H., Salmon, J., Collins, P., Al-Hamdani, M., Boffo, M., Wiers, R. W. (2017). Distorted beliefs about luck and skill and their relation to gambling problems and gambling behaviour in Dutch gamblers. Frontiers in Psychology, 8, 2245. https://doi.org/10.3389/fpsyg.2017.02245

Derevensky, J. L., Shek, D. T. ., \& Merrick, J. (2011). Youth gambling. The hidden addiction. Berlin: de Gruyter https://doi.org/10.1515/9783110255690

Ferris, J., \& Wynne, H. (2001). The Canadian Problem Gambling Index: Final report. Ottawa: Canadian Centre on Substance Abuse. https://doi.org/10.1007/s10899-0109224-y

Gilbert, G. E., \& Prion, S. (2016). Making sense of methods and measurement: lawshe's content validity index. Clinical Simulation in Nursing, 12(12), 530-531. https://doi.org/10.1016/j.ecns.2016.08.002

González-Roz, A., Fernández-Hermida, J. R., Weidberg, S., Martínez-Loredo, V., \& Secades-Villa, R. (2017). Prevalence of problem gambling among adolescents: A comparison across modes of access, gambling activities, and levels of severity. Journal of Gambling Studies, 33(2), 371-382. https://doi.org/10.1007/s10899-016$9652-4$

Hair, J. F., Babin, B. J., Anderson, R. E., \& Black, W. C. (2018). Multivariate data analysis (8th ed.). Boston, MA: Cengage Learning. doi: 10.1002/9781119409137.ch4.

Heinz, A., Romanczuk-Seiferth, N., \& Potenza, M. N. (2019). Gambling disorder. Cham, Switzerland: Springer Nature. doi: 10.1007/978-3-030-03060-5 
Henseler, J., Hubona, G., \& Ray, P. A. (2016). Using PLS path modeling in new technology research: updated guidelines. Industrial Management \& Data Systems, 116(1), 2-20. https://doi.org/10.1108/imds-09-2015-0382

Hu, L.t., \& Bentler, P. M. (1999). Cutoff criteria for fit indexes in covariance structure analysis: Conventional criteria versus new alternatives. Structural Equation Modeling, 6(1), 1-55. https://doi.org/10.1080/10705519909540118

Hubert, P., \& Griffiths, M. D. (2018). A comparison of online versus offline gambling harm in portuguese pathological gamblers: An empirical study. International Journal of Mental Health and Addiction, 16(5), 1219-1237. https://doi.org/10.1007/s11469$017-9846-8$

Jonsson, J. (2019). Preventing problem gambling: Focus on overconsumption. Doctoral dissertation. Department of Psychology, Stockholm University, Stockholm.

Killick, E. A., \& Griffiths, M. D. (2019). In-play sports betting: a scoping study. International Journal of Mental Health and Addiction, 17(6), 1456-1495. https://doi.org/10.1007/s11469-018-9896-6

Latvala, T., Lintonen, T., \& Konu, A. (2019). Public health effects of gambling - Debate on a conceptual model. BMC Public Health, 19(1), 1-16. https://doi.org/10.1186/s12889-019-7391-z

Lesieur, H.R.\& Blume, S.B. (1987). The South Oaks Gambling Screen (SOGS): A new instrument for the identification of pathological gamblers. American Journal of Psychiatry, 144, 1184-1188. https://doi.org/10.1176/ajp.144.9.1184

Loo, J. M. Y., Oei, T. P. S., \& Raylu, N. (2011). Psychometric evaluation of the problem gambling severity index-chinese version (PGSI-C). Journal of Gambling Studies, 27(3), 453-466. https://doi.org/10.1007/s10899-010-9221-1

Lopez-Gonzalez, H., Estévez, A., \& Griffiths, M. D. (2018). Spanish validation of the 
Problem Gambling Severity Index: A confirmatory factor analysis with sports bettors. Journal of Behavioral Addictions, 7(3), 814-820. https://doi.org/10.1556/2006.7.2018.84

Maarefvand, M., Mardaneh-Jobehdar, M., Ghiabi, M., Rafimanesh, H., Mohammadi, A., Morshedi, Z., ... Hosseinzadeh, S. (2019). Designing and evaluating the validity and reliability of the persian gambling disorder screening questionnaire. Addiction \& Health, 11(2), 110-119. https://doi.org/10.22122/ahj.v11i2.235

McRobert, C. J., Hill, J. C., Smale, T., Hay, E. M., \& van der Windt, D. A. (2018). A multimodal recruitment strategy using social media and internet-mediated methods to recruit a multidisciplinary, international sample of clinicians to an online research study. Plos One, 13(7), e0200184. https://doi.org/10.1371/journal.pone.0200184

Montazeri, A., Vahdaninia, M., Ebrahimi, M., \& Jarvandi, S. (2003). The hospital anxiety and depression scale (HADS): Translation and validation study of the Iranian version. Health and Quality of Life Outcomes, 1, 1-5. https://doi.org/10.1186/1477-7525-114

Newall, P. W. S., Moodie, C., Reith, G., Stead, M., Critchlow, N., Morgan, A., \& Dobbie, F. (2019). Gambling marketing from 2014 to 2018: A literature review. Current Addiction Reports, 6(2), 49-56. https://doi.org/10.1007/s40429-019-00239-1

Olason, D. T., Kristjansdottir, E., Einarsdottir, H., Haraldsson, H., Bjarnason, G., \& Derevensky, J. L. (2010). Internet gambling and problem gambling among 13 to 18 year old adolescents in Iceland. International Journal of Mental Health and Addiction, 9(3), 257-263. https://doi.org/10.1007/s11469-010-9280-7

Orford, J., Wardle, H., Griffiths, M. D., Sproston, K. \& Erens, B. (2010). PGSI and DSMIV in the 2007 British Gambling Prevalence Survey: Reliability, item response, factor structure and inter-scale agreement. International Gambling Studies, 10, 31-44. 
https://doi.org/10.1080/14459790903567132

Otto, J. L., Smolenski, D. J., Garvey Wilson, A. L., Evatt, D. P., Campbell, M. S., Beech, E. H., ... Belsher, B. E. (2020). A systematic review evaluating screening instruments for gambling disorder finds lack of adequate evidence. Journal of Clinical Epidemiology, 120, 86-93. https://doi.org/10.1016/j.jclinepi.2019.12.022

So, R., Matsushita, S., Kishimoto, S., \& Furukawa, T. A. (2019). Development and validation of the Japanese version of the Problem Gambling Severity Index. Addictive Behaviors, 98, 105987. https://doi.org/10.1016/j.addbeh.2019.05.011

Stevens, M \& Young, M (2008). Gambling screens and problem gambling estimates: A parallel psychometric assessment of the South Oaks Gambling Screen and the Canadian Problem Gambling Index. Gambling Research, 20(1), 13-36.

Stinchfield, R. (2013). A review of problem gambling assessment instruments and brief screens. In: Richard, D. C. S., Blaszczynski A., \& Nower, L. (Eds.), The WileyBlackwell handbook of disordered gambling (pp. 165-203). Chichester, UK: Wiley. https://doi.org/10.1002/9781118316078

Tabachnick, B. G., \& Fidell, L. S. (2014). Using multivariate statistics $6^{\text {th }}$ edition. Harlow, UK: Pearson Education.

Volberg, R. A., Gupta, R., Griffiths, M. D., Ólason, D. T., \& Delfabbro, P. (2010). An international perspective on youth gambling prevalence studies. International Journal of Adolescent Medicine and Health, 22(1), 3-38. https://doi.org/10.1515/9783110255690.21

Wardle, H., Reith, G., Langham, E., \& Rogers, R. D. (2019). Gambling and public health: We need policy action to prevent harm. BMJ, 365, 1-5, 11807. https://doi.org/10.1136/bmj.11807

Welte, J. W., Barnes, G. M., Tidwell, M. C. O., \& Wieczorek, W. F. (2017). Predictors of 
problem gambling in the U.S. Journal of Gambling Studies, 33(2), 327-342. https://doi.org/10.1007/s10899-016-9639-1

Zhang, X., Shi, J., \& Tao, R. (2017). Substance and non-substance addiction. Advances in Experimental Medicine and Biology. Singapore: Springer Nature Singapore. https://doi.org/10.1007/978-981-10-5562-1

Zigmond, A. S., \& Snaith, R. P. (1983). The hospital anxiety and depression scale. Acta Psychiatrica Scandinavica, 67(6), 361-370. https://doi.org/10.1111/j.16000447.1983.tb09716.x 
Table 1. Demographic characteristics of the sample $(\mathrm{N}=858)$

\begin{tabular}{rcc}
\hline \multicolumn{1}{l}{ Item } & Frequency $(\mathrm{N})$ & Percentage (\%) \\
\hline Problem gambling & & \\
Non-gamblers & 287 & 33.4 \\
Low-risk gamblers & 125 & 14.6 \\
Moderate-risk & 255 & 29.7 \\
Problem gamblers & 191 & 22.3 \\
\hline Age $\quad$ 18 to 24 years & 242 & 28.2 \\
24 to 30 years & 384 & 44.75 \\
Over 30 years & 232 & 27.05 \\
\hline Female & & 233 \\
Mender $\quad$ Male & 27.2 & 625 \\
\hline Pducation $\quad 72.8$ & 8.8 \\
Primary & & 65.9 \\
Bachelor & 75 & 25.5 \\
\hline Masters + & 566 & 37.9 \\
\hline Enemployed & 218 & 62.1 \\
\hline
\end{tabular}


Table 2. Study schedule of survey validation

\begin{tabular}{|c|c|c|c|c|c|}
\hline Study stage & Duration & $\begin{array}{l}\text { Instrument } \\
\text { pre-testing }\end{array}$ & $\begin{array}{l}\text { Collecting } \\
\text { data }\end{array}$ & $\begin{array}{c}\text { Data } \\
\text { analysis }\end{array}$ & $\begin{array}{l}\text { Test-retest } \\
\text { validity }\end{array}$ \\
\hline \multicolumn{6}{|l|}{ Pre-testing } \\
\hline Domain content & 10 weeks & $x$ & & & \\
\hline Transcultural & 3 weeks & $x$ & & & \\
\hline Expert panel & 4 weeks & $x$ & & & \\
\hline Pilot study & 2 weeks & $x$ & & & \\
\hline \multicolumn{6}{|l|}{ Validation } \\
\hline Informed Consent & & $x$ & $x$ & & \\
\hline Demographic & 16 weeks & $x$ & $x$ & $x$ & \\
\hline PGSI & & $x$ & $x$ & $x$ & $x$ \\
\hline HADS & & & $x$ & $x$ & \\
\hline Total time & & 19 weeks & 16 weeks & 4 weeks & 4-6 weeks \\
\hline \multicolumn{6}{|c|}{ Total time: 45 weeks: June 2019 to March 2020} \\
\hline \multicolumn{6}{|c|}{$\begin{array}{l}\text { Note: PGSI: Problem Gambling Severity Index, HADS= Hospital Anxiety and Depression } \\
\text { Scale }\end{array}$} \\
\hline
\end{tabular}


Table 3. Item-total statistics

\begin{tabular}{|c|c|c|c|c|}
\hline \multicolumn{5}{|c|}{ Item-Total Statistics } \\
\hline \multirow[t]{2}{*}{ Item } & Factor & Corrected Item-Total & Cronbach's $\alpha$ if & VIF \\
\hline & loading & Correlation & Item Deleted & \\
\hline 1 & .743 & .66 & .891 & 2.07 \\
\hline 2 & .802 & .73 & .886 & 2.46 \\
\hline 3 & .773 & .70 & .888 & 2.01 \\
\hline 4 & .734 & .66 & .891 & 1.85 \\
\hline 5 & .772 & .70 & .888 & 2.08 \\
\hline 6 & .701 & .62 & .894 & 1.66 \\
\hline 7 & .732 & .65 & .892 & 1.79 \\
\hline 8 & .747 & .67 & .891 & 1.95 \\
\hline 9 & .722 & .65 & .893 & 1.78 \\
\hline
\end{tabular}

Note: VIF=variance inflation factor 


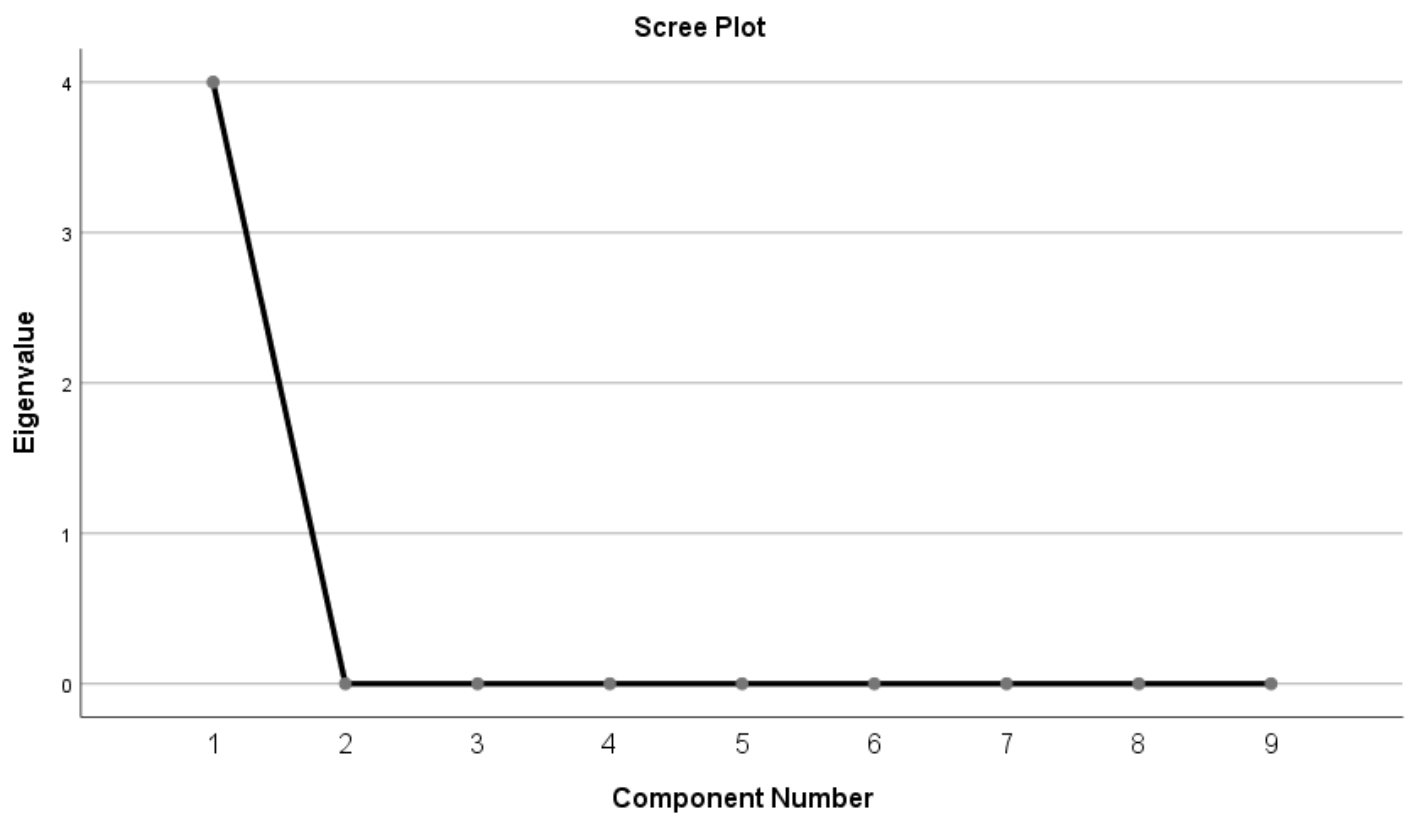

Figure 1. Scree plot 


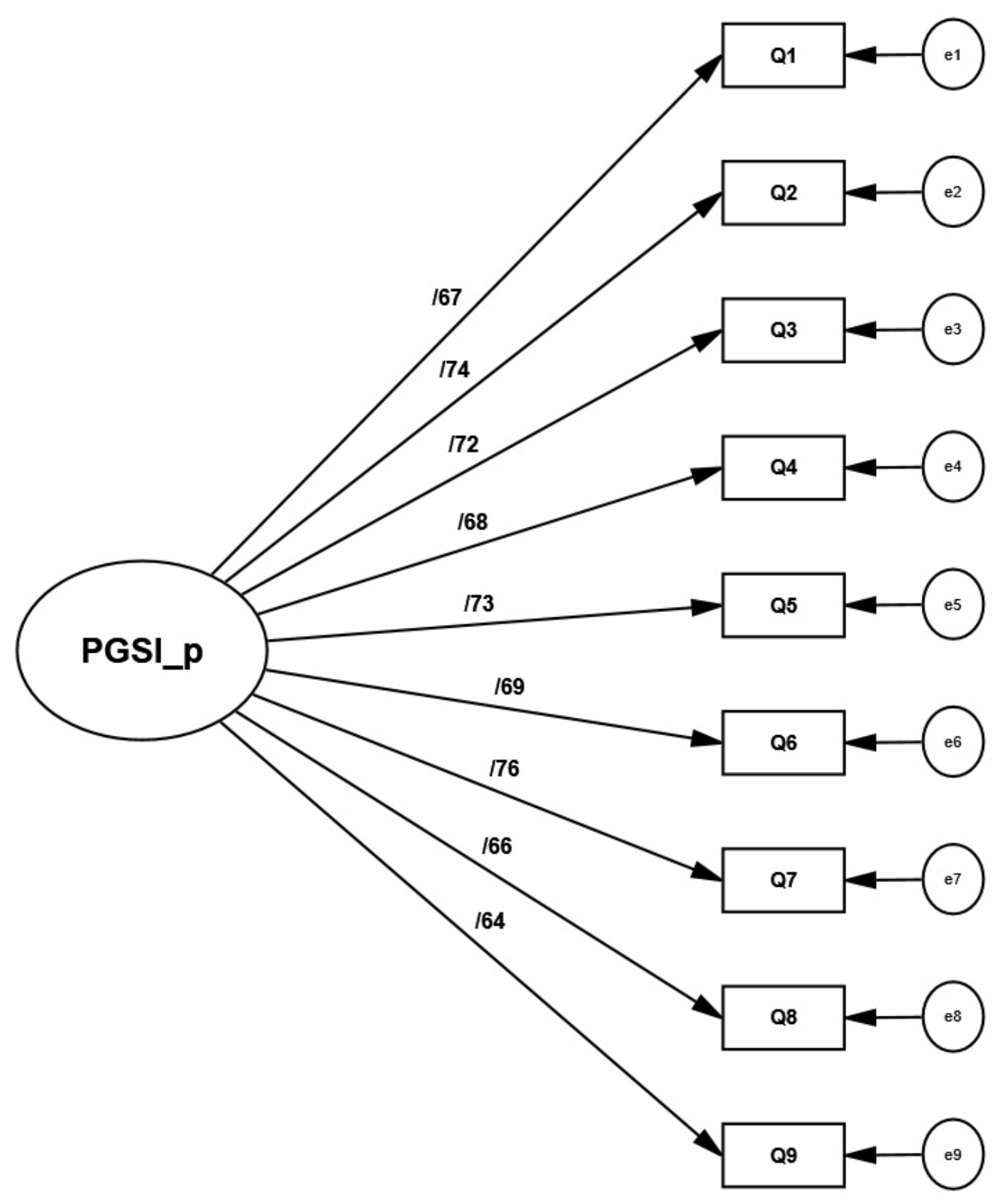

Figure 2: Unidimensional model and factor loadings of the Persian PGSI 